\title{
Fucus vesiculosus extracts as natural antioxidants for improvement of physicochemical properties and shelf life of pork patties formulated with oleogels
}

\author{
Rubén Agregán, ${ }^{a}$ Francisco J Barba, ${ }^{b} \odot$ Mohsen Gavahian, ${ }^{c} \odot$

 \\ Isabel CFR Ferreira, ${ }^{f} \oplus$ Andrea Carla da Silva Barretto $_{\odot}$ \\ and José M Lorenzo ${ }^{a^{*}}$
}

\begin{abstract}
BACKGROUND: There is limited information in the literature concerning the feasibility of using algal extracts as natural additives for improvement of the quality and shelf-life of meat products. Hence, a Fucus vesiculosus extract (FVE) at the concentrations of $250 \mathrm{mg} \mathrm{kg}^{-1}$ (FVE-250), $500 \mathrm{mg} \mathrm{kg}^{-1}$ (FVE-500) and $1000 \mathrm{~g} \mathrm{~kg}^{-1}$ (FVE-1000) were added to pork patties with linseed oil oleogel as a fat replacer.

RESULTS: Total polyphenol content of FVE was determined to be $20 \mathrm{~g}$ phloroglucinol equivalents $100 \mathrm{~g}^{-1}$ extract. Antioxidant values ranged from $37.5 \mu \mathrm{mol}$ of Trolox equivalents (TE) $\mathrm{g}^{-1}$ (FRAP assay) to $2111 \mu \mathrm{mol} \mathrm{TE} \mathrm{g}^{-1}$ extract (ABTS assay). Regarding oxidation stability, FVE-1000 showed the lowest values of thiobarbituric acid-reactive substance and carbonyl content. On the other hand, FVE did not improve color, surface discoloration or odor attributes of patties during storage. Sensory evaluation revealed that there was no significant difference among all studied samples.
\end{abstract}

CONCLUSION: Although FVEs have a high polyphenol content and antioxidant activities, they are not effective oxidation inhibitors for long-term storage of meat products. Therefore, additional measures or compounds should be considered when FVE is the only antioxidant in meat products.

(C) 2019 Society of Chemical Industry

Keywords: seaweed extract; lipid and protein oxidation; physicochemical parameters; sensory analysis; antioxidant activity

\section{INTRODUCTION}

Changes in muscle foods due to oxidative reactions, both in lipids and proteins, have a strong impact on meat quality, causing a reduction in shelf life as well as a considerable loss of nutrients. ${ }^{1}$ Oxidation reactions may occur in a variety of food products, including meat and meat products, as phenomena responsible for the deterioration of nutritional and sensory quality. ${ }^{1}$ The changes in organoleptic attributes may result in consumer dissatisfaction and product rejection. For instance, according to Carpenter et al. ${ }^{2}$ variations in color parameters could affect consumers' purchase decisions, as the product color is often regarded as an indicator of product freshness and quality. ${ }^{3}$ Proteins can also be deteriorated by oxidation, leading to loss of amino acids and alterations in their functionality, with negative consequences for product texture. ${ }^{4}$

The scientific community, as well as the meat industry, considers the spoiling of muscle foods as the result of oxidative reactions to be a challenge, leading them to develop strategies to slow down these processes. ${ }^{1}$ To keep oxidation reactions in lipids and/or proteins under control, synthetic antioxidants, such as butylated hydroxyl toluene $(\mathrm{BHT})$ and butylated hydroxyl anisole $(\mathrm{BHA})$, are
* Correspondence to: JM Lorenzo, Centro Tecnológico de la Carne de Galicia, Adva. Galicia $n^{\circ}$ 4, Parque Tecnológico de Galicia, San Cibrao das Viñas, Ourense, Spain. E-mail:jmlorenzo@ceteca.net

a Centro Tecnológico de la Carne de Galicia, Adva. Galicia $n^{\circ}$ 4, Parque Tecnológico de Galicia, San Cibrao das Viñas, Ourense, Spain

b Nutrition and Food Science Area, Preventive Medicine and Public Health, Food Science, Toxicology and Forensic Medicine Department, Faculty of Pharmacy, Universitat de València, València, Spain

c Product and Process Research Center, Food Industry Research and Development Institute, Hsinchu City, Taiwan, ROC

d Department of Food Science, Faculty of Food Engineering, University of Campinas (UNICAMP), São Paulo, Brazil

e Area de Tecnologia de los Alimentos, Facultad de Ciencias de Ourense, Universidad de Vigo, Ourense, Spain

f Mountain Research Centre (CIMO), Polytechnic Institute of Bragança (IPB), Campus de Santa Apolonia, Bragança, Portugal

g Department of Food Technology and Engineering, Institute of Biosciences, Humanities and Exact Sciences (IBILCE), São Paulo State University, São José do Rio Preto, Brazil 
added to meat, fats and oils. ${ }^{5}$ However, because of possible toxic effects on human health, serious concerns are raised regarding the addition of these substances to food products. ${ }^{6}$

To overcome this inconvenience, as well as, following consumer trends, to consume more natural products, certain substitutes for synthetic antioxidants have been introduced. ${ }^{7}$ Plant extracts or plant-derived compounds increasingly represent alternatives to synthetic additives, which could contribute to delaing oxidation and stabilizing color and texture in foods. ${ }^{1}$ The marine environment has been shown to be rich in natural compounds that are rare in terrestrial ecosystems. For example, notably macroalgae and their extracts have many functional properties ${ }^{8}$ and constitute a valuable source of antioxidant agents, such as carotenoids, polyphenols, alkaloids, tocopherol and terpenes. ${ }^{9}$ Fucus vesiculosus is rich in phlorotannins which are particular polyphenolic compounds of brown algae. ${ }^{10}$ Some phlorotannins have shown higher antioxidant capacity than commercial antioxidants and are of interest as natural antioxidant alternatives.

Beef burgers are popular products throughout the world. ${ }^{11}$ However, consumers tend to perceive animal fats and meat as unhealthy. ${ }^{11}$ The replacement of these fats with vegetable oils turns out to be a successful strategy to improve the nutritional profile of muscle foods. Linseed oil might be a good alternative to animal fat for production of these food products. It is the major seed oil, with an $\alpha$-linolenic acid content of ca $50-55 \%$. Moreover, it has an $\alpha$-linoleic acid content of ca $15-18 \%$, demonstrating a positive balance between polyunsaturated, monounsaturated and saturated fatty acids (FAs). ${ }^{12}$ Unfortunately, the replacement of hard fats with oils usually leads to a decrease in product quality, resulting in altered properties, concerning mainly textural attributes and sensory characteristics. ${ }^{13}$ Consequently, the structuring of edible oils, while respecting their fat composition, is actively researched. The use of gelling agents has recently proved to be an efficient approach for this purpose. These agents are organic liquids, known as oleogels, that are encased in thermoreversible three-dimensional gel networks. ${ }^{14}$ These oleogels maintain the FA profile of the oils, as well as the functionality and texture of the final product.

In this context, the aim of this investigation was to evaluate the effectiveness of $F$. vesiculosus extracts to extend the shelf life of pork patties manufactured with linseed oil oleogels and packaged under conditions of modified atmosphere during refrigerated storage. The physicochemical properties and sensory attributes of seaweed-based pork patty formulations were compared with control samples that were formulated without any antioxidant or with BHT.

\section{MATERIAL AND METHODS}

\section{Algal material}

The brown seaweed F. vesiculosus (Kingdom: Chromista, Phylum: Ochrophyta, Class: Phaeophyceae and Order: Fucales) was supplied by Portomuiños company (A Coruña, Spain). The algal material was collected at the Galician Atlantic coast, in the area of Camariñas, a village close to the town of A Coruña (NW Spain). It was subjected to milling with a conventional homemade mincer until particles $\leq 0.8 \mathrm{~mm}$ were obtained using a porous mesh. After this treatment, the ground seaweed was packaged in plastic bags under vacuum at $75 \%$ and stored at $-20^{\circ} \mathrm{C}$ until further use.

\section{Obtaining $F$. vesiculosus extracts}

The algal material was extracted with a mixture of water/ethanol $(50: 50, v / v)$ in the proportion of $1: 10(\mathrm{w} / \mathrm{v})$ for $30 \mathrm{~min}$, using an ultrasound bath at room temperature. The solid residue was separated from the solvent by centrifugation for $10 \mathrm{~min}$ at 3000 $\mathrm{xg}$ and $4{ }^{\circ} \mathrm{C}$. The supernatant was collected and filtered under vacuum using a simple laboratory filter. The filtrate was subjected to vacuum at $40{ }^{\circ} \mathrm{C}$ using a rotary evaporator to remove the ethanol. Finally, the aqueous extract was freeze-dried and kept at $-20^{\circ} \mathrm{C}$ until further use. The seaweed extract was resuspended in water:ethanol (50:50, v/v) before its use.

\section{Preparation of linseed oil oleogel}

The oleogel used in the present study consisted of an oil phase and a mixture of two structuring agents ( $\mathrm{Y}$-oryzanol and $\beta$-sitosterol). The oil phase was commercial linseed oil (Vitaquell ${ }^{\circledR}$ ) containing $72 \%$ polyunsaturated (ca 55\% $\alpha$-linoleic), $19 \%$ monounsaturated and $9 \%$ saturated FAs. The $\mathrm{X}$-oryzanol and $\beta$-sitosterol were mixed in a ratio of $60: 40(\mathrm{w} / \mathrm{w})$. This ratio corresponds to a mole ratio of 1:1 and was reported to be the ratio that allows formation of the firmest transparent gel. Y-Oryzanol and $\beta$-sitosterol were purchased from Oryza Co. (Japan) and Sigma-Aldrich (France), respectively. Both structuring agents were dispersed by stirring until solubilization, together with the linseed oil, at $80^{\circ} \mathrm{C}$ for $30 \mathrm{~min}$. Then, the mixture was left to cool at room temperature until formation of the gel.

\section{Manufacture of pork patties}

A total of 125 patties divided into 25 units per treatment (5 treatments) were manufactured in the pilot plant at the Centro Tecnolóxico da Carne, Ourense, Spain. Different treatments were carried out as follows: patties with seaweed $F$. vesiculosus extract (FVE) as antioxidant incorporated at 250 (FVE-250), 500 (FVE-500) and 1000 (FVE-1000) $\mathrm{mg} \mathrm{kg}^{-1}$; patties with BHT added at $200 \mathrm{mg} \mathrm{kg}^{-1}$ as conventional synthetic antioxidant; and patties without antioxidant (CO) as control. Patties were manufactured with prime cuts of pig loin purchased in a local market. The meat samples were chopped under refrigeration in a mincer machine (La Minerva, $A / E$ $22 \mathrm{R}$, Bologna, Italy) and then mixed with linseed oil oleogel, salt and water in the proportions indicated in Table 1. Patty samples of $60 \mathrm{~g}$ were produced using a burger maker (A-2000, Gaser, Girona, Spain). After production, the patties were wrapped in polystyrene trays of $300 \mathrm{~mm}$ thickness under $80 \% \mathrm{O}_{2}$ and $20 \% \mathrm{CO}_{2}$, using a LARI3/Pn T-VG-R-SKIN heat sealer (Ca. Ve.Co., Palazzolo, Italy). Polyethylene film [thickness $74 \mathrm{~mm}$, with permeability less than $2 \mathrm{~mL}\left(\mathrm{~m}^{2} \text { bar day }{ }^{-1}\right)^{-1}$ ] appropriate for gas mixtures was used (Viduca, Alicante, Spain) and stored at $2 \pm 1{ }^{\circ} \mathrm{C}$ under light in order to simulate the storage condition of supermarkets. Lux values varied in the range of 15-20 as a function of the tray position (Digital luxometer HT 306, Faenza, Italy). A conventional light source was used in this study, i.e. no wavelength or range of lengths, such as UV, was filtered. Pork patties were analyzed at the initial day for chemical composition and FA profile, and at $0,7,11,15$ and 18 days of storage for physicochemical parameters $(\mathrm{pH}$ and color) and stability to oxidation [values of thiobarbituric acid-reactive substance (TBARs) and protein oxidation]. In addition, odor and visual acceptance were evaluated at all sampling time points, whereas preference tests were performed at the beginning of storage [ 5 patties (units) per treatment]. At each sampling time point, 4 units of each type were taken for analysis.

\section{Total phenolic content (TPC) and evaluation of the antioxidant activity of the seaweed extracts}

TPC and total antioxidant capacity (evaluated with radical cation decolorization assay (ABTS), oxygen radical absorbance capacity 
Table 1. Ingredient proportions used in the manufacture of pork patties with several added antioxidants

Treatment

\begin{tabular}{|c|c|c|c|c|c|}
\hline Ingredient $\left(\mathrm{g} 100 \mathrm{~g}^{-1}\right)$ & $\mathrm{CO}$ & BHT & FVE-250 & FVE-500 & FVE-1000 \\
\hline Pork loin & 87 & 87 & 87 & 87 & 87 \\
\hline Linseed oil oleogel & 5 & 5 & 5 & 5 & 5 \\
\hline Salt & 1.04 & 1.04 & 1.04 & 1.04 & 1.04 \\
\hline Water & 6.96 & 6.96 & 6.96 & 6.96 & 6.96 \\
\hline BHT & 0 & 0.02 & 0 & 0 & 0 \\
\hline Seaweed extract & 0 & 0 & 0.025 & 0.05 & 0.1 \\
\hline
\end{tabular}

Abbreviations: BHT, addition of $200 \mathrm{mg} \mathrm{kg}^{-1}$ tert-butyl-4-hydroxytoluene; CO, control without any antioxidant; FVE-250, FV-500 and FV-1000, addition of Fucus vesiculosus extract at 250, 500 and $1000 \mathrm{mg} \mathrm{kg}^{-1}$, respectively.

assay (ORAC), radical scavening assay (DPPH) and ferric reducing antioxidant power (FRAP) assays) were determined according to methods previously described in detail by Agregán et al. ${ }^{9}$ who specialize in research on algal samples.

\section{Chemical composition and fatty acid (FA) profile of pork patties}

Protein, moisture and ash content were determined following ISO recommended standards, i.e. ISO 937:1978, ${ }^{15}$ ISO 1442:1997, ${ }^{16}$ ISO 936:1998, ${ }^{17}$ respectively. Fat was extracted using an extractor (Ankom XT10, ANKOM Technology Corp., Macedon, NY, USA) and was quantified following the official AOCS procedure Am 5-04. ${ }^{18}$ The FA profile was determined according to methods described by Fernandes et al. ${ }^{7}$ using a gas chromatograph equipped with an FID detector (GC Agilent 7890 N; Agilent Technologies Spain, S.L., Madrid, Spain).

\section{Determination of physical parameters of pork patties}

A portable digital pH-meter (Hanna Instruments, Eibar, Spain) equipped with a penetration probe was employed to measure the $\mathrm{pH}$ of pork patties. The color parameters of the CIELAB color space system, including lightness $\left(L^{*}\right)$, redness $\left(a^{*}\right)$ and yellowness $\left(b^{*}\right)$, were determined using a portable colorimeter (Konica Minolta CM-600d, Osaka, Japan) equipped with a pulsed xenon arc lamp filtered to D65 illuminant lighting conditions, with a zero-degree viewing angle geometry and aperture size of $8 \mathrm{~mm}$. The color was measured at six different points on the patty surface after 30 min of exposure to the environmental atmosphere.

\section{Determination of protein and lipid oxidation indices}

Protein oxidation was evaluated based on the procedure described by Mercier et al. ${ }^{19}$ and results were expressed as $\mathrm{nmol}$ carbonyl $\mathrm{mg}^{-1}$ protein. The stability of pork patty lipid was assessed using the TBARs test, following the method proposed by Vyncke $^{20}$ and expressing the results as mg malonaldehyde (MDA) $\mathrm{kg}^{-1}$ pork patty.

\section{Sensory evaluation of raw and cooked pork patties}

Sensory analysis of raw and cooked patties was carried out by 16 trained panellists who were selected from the Centro Tecnolóxico da Carne. A test of acceptance of raw patties was conducted at 0 , $7,11,15$ and 18 days of storage, as well as a test of acceptance of and preference for cooked patties. In the acceptance test, panelists accepted or rejected the samples, and in the preference test, panelists classified the samples from best to worst according to taste. In the acceptance test, panelists scored raw samples based on color, surface discoloration and odor, and they scored cooked samples with respect to odor and taste using a 5-point hedonic scale (from 1, excellent to 5, not acceptable). In the test of preference for cooked samples, panelists with a score of 1, favorite. Patties were cooked in an oven (Rational Combimasterplus CMP61, Germany) until a core temperature of $70{ }^{\circ} \mathrm{C}$ was reached. Sensory tests were carried out in an individual cabin illuminated with white light. Samples were served on disposable plastic dishes marked with 3-digit random numbers. ${ }^{21}$ Water and unsalted toasted bread were provided at the beginning and between tests of samples to remove residual flavors from the mouth.

\section{Statistical analyses}

Statistical analysis of the results was conducted using the IBM SPSS Statistics ${ }^{\circledR} 23.0$ program (IBM Corporation, Somers, NY, USA). One-way analysis of variance (ANOVA) was applied to all variables assessed in this study. Time and different treatments were taken to be fixed variables and chemical composition (moisture, fat, protein and ash content), FA profile, $\mathrm{pH}$, color and oxidation parameters (TBARs values and protein oxidation) were taken to be independent variables. The least square means (LSM) were separated using Duncan's post hoc test (significance level $P<0.05$ ). Friedman's test (significance level $\alpha<0.05$ ) was applied to cooked patties in the sensorial analysis to determine the panelists' preferences.

\section{RESULTS AND DISCUSSION}

\section{Total phenolic content and antioxidant capacity of $F$.} vesiculosus extracts

The TPC of FVEs was ca $20 \mathrm{~g}$ of phloroglucinol equivalents (PGE) $100 \mathrm{~g}^{-1}$ extract. These results contrast with those obtained by Agregán et al. ${ }^{8}$ who reported very low contents of phenolic compounds in aqueous extracts of several brown seaweeds (Bifurcaria bifurcate, F. vesiculosus and Ascophyllum nodosum), with values ranging from 0.96 to $1.99 \mathrm{~g}$ PGE $100 \mathrm{~g}^{-1}$ FVE. Wang et al. ${ }^{22}$ found $17.6 \mathrm{~g}$ PGE $100 \mathrm{~g}^{-1}$ FVE in a aqueous extracts of $F$. vesiculosus, which is similar to that found in the present study. According to these authors, ${ }^{22}$ phenolic compounds are more easily extractable with polar organic solvents than with water. Aqueous mixtures of methanol, ethanol or acetone were recommended for this purpose, $^{23}$ the use of which resulted in a yield of $24.2 \mathrm{~g}$ PGE $100 \mathrm{~g}^{-1} \mathrm{FVE}$ in a $70 \%(\mathrm{v} / \mathrm{v})$ acetone extract from $F$. vesiculosus, not higher than that found in the current investigation. Moreover, almost all brown algae tested in the study carried out by 
Waterman and Mole ${ }^{23}$ had higher amounts of polyphenols than the red and green algae.

Similarly, according to Jiménez-Escrig et al. ${ }^{24}$ the brown seaweeds tested had higher TPCs than the red seaweeds, whereas the organic polar solvents were found to be more efficient in extracting polyphenolic compounds than water. However, no TPC value obtained for the seaweed extracts analyzed exceeded $3.5 \mathrm{~g}$ PGE $100 \mathrm{~g}^{-1} \mathrm{FVE}$, which is considerably lower than the values obtained in the present study for the FVEs, even when a combination of organic polar solvents, such as methanol and water, was used at the same ratios as applied in the current investigation. Jiménez-Escrig et al. ${ }^{24}$ and Farvin and Jacobsen ${ }^{25}$ reported high TPCs in all the Fucus species investigated. Generally, brown algae are richer in phenolic compounds than other types of algae due to their high content of phlorotannins, a family of polyphenol compounds exclusively found in brown algae in special vesicles (physodes) within the cells.

The antioxidant value obtained using the ABTS test was $2111 \pm 22.63 \mu \mathrm{mol}$ TE $\mathrm{g}^{-1}$ FVE $\left(\mathrm{IC}_{50}, 0.65 \pm 0.01\right)$. In a previous study, Agregán et al. ${ }^{8}$ reported lower values, ranging from 100 to $1100 \mu \mathrm{mol}$ TE/g Trolox equivalents FVE in aqueous extracts of three brown seaweeds ( $A$. nodosum, $F$. vesiculosus and Bifurcaria bifurcata) using the same assay (which showed the FVE value to be the highest). In this case, the lower values could be related to the lower polyphenol contents, since all these extracts had much lower concentrations of polyphenols than the extract used in the present study. Moreover, the positive correlation between polyphenol content and antioxidant capacity has been well documented. ${ }^{22,25}$

As for the ORAC assay, a value of $1598.5 \pm 34.65 \mu \mathrm{mol} \mathrm{TE} \mathrm{g}^{-1} \mathrm{FVE}$ was found, which is comparable to that reported by Wang et al. ${ }^{22}$ (i.e. $1417 \mu \mathrm{mol} \mathrm{TE} \mathrm{g}^{-1}$ FVE obtained with a $70 \%$ acetone extract) for A. nodosum. However, higher values were found by these authors when they used $70 \%$ acetone to obtain the extracts from $F$. vesiculosus and Fucus serratus (2567 and $2567 \mu \mathrm{mol} \mathrm{TE} / \mathrm{g}^{-1} \mathrm{FVE}$, respectively), and also in water extracts of the Ascophylum nodosum (2000 $\mu \mathrm{mol}$ TE $\left./ \mathrm{g}^{-1} \mathrm{FVE}\right)$. However, Agregán et al. ${ }^{8}$ reported a considerably lower value for the water extract from $F$. vesiculosus (756.5 $\left.\mu \mathrm{mol} \mathrm{TE} / \mathrm{g}^{-1} \mathrm{FVE}\right)$.

The DPPH assay of FVE revealed values of $278 \pm 1.41 \mu \mathrm{mol}$ TE $\mathrm{g}^{-1}$ extract $\left(\mathrm{IC}_{50}, 3.47 \pm 0.01 \mathrm{~g} \mathrm{~L}^{-1}\right)$. In this context, Agregán et al. ${ }^{8}$ also used the DPPH assay to measure antioxidant capacity, reporting a lower value in the water extract from $F$. vesiculosus $\left(135.31 \mu \mathrm{mol}\right.$ TE/g FVE) with a consequently higher value for its $I C_{50}$ $\left(4.19 \mathrm{~g} \mathrm{~L}^{-1}\right)$, as the lower $\mathrm{IC}_{50}$ value of the extract reveals higher radical-scavenging activity. Farvin and Jacobsen ${ }^{25}$ found that the water extracts of 2 Fucus species, namely F. vesiculosus and F. serratus, had the highest antioxidant activities $\left(\mathrm{IC}_{50}\right.$ of $0.0083 \mathrm{~g} \mathrm{~L}^{-1}$ in both cases) among other studied species. The ethanol extracts of these algal species also exhibited the highest radical-scavenging activities, with an $\mathrm{IC}_{50}$ of $0.0099 \mathrm{~g} \mathrm{~L}^{-1}$ and $0.0092 \mathrm{~g} \mathrm{~L}^{-1}$ for $F$. vesiculosus and F. serratus, respectively. The $\mathrm{IC}_{50}$ values reported in the study by Farvin and Jacobsen ${ }^{25}$ were lower than those obtained for the FVEs analyzed in the current study, indicating a higher antioxidant capacity of these extracts in the previously conducted research. In another study, Rajauria et $a{ }^{26}$ found lower antioxidant capacities also in water and methanol extracts from Himanthalia elongata alga, in comparison with those of the previous extracts. ${ }^{25}$ According to Connan et al., ${ }^{27}$ environmental factors and intrinsic features of algae, such as light or salinity and age or length, could lead to notable variations in the phenolic content of algae that may be responsible for the differences observed in their antioxidant capacities.

A value of $37.5 \pm 2.12 \mu \mathrm{mol}$ TE g ${ }^{-1}$ extract was recorded when a FRAP assay of the FVE was used. This result was very close to the results reported by Rajauria et al. ${ }^{26}$, i.e. $41.15 \mu \mathrm{mol} \mathrm{TE} \mathrm{g}{ }^{-1}$ FVE and $46.75 \mu \mathrm{mol}$ TE $\mathrm{g}^{-1}$ FVE obtained with $40 \%$ and $60 \%$ methanol extracts, respectively, from $H$. elongata brown seaweed. The FRAP assay was also used by Agregán et al. ${ }^{8}$ to measure the antioxidant capacity of seaweeds, and a slightly higher value was found in the aqueous extract from $F$. vesiculosus $(51.66 \mu \mathrm{mol} \mathrm{TE} / \mathrm{g}$ FVE) compared to the values in extracts from $A$. nodosum and $B$. bifurcata (7.52 and $26.93 \mu \mathrm{mol} \mathrm{TE} \mathrm{g}^{-1}$ FVE respectively).

\section{Effect of FVE incorporation on the proximate composition and FA profile of pork patties}

As shown in Table 2, which gives the chemical composition (protein, fat, moisture and ash content) and FA profile of pork patties, no significant differences in chemical composition were observed among the different formulations $(P>0.05)$. Moreover, the different concentrations of FVE in patties did not influence the percent values for moisture, fat, protein and ash. These results are in agreement with those reported by Rodríguez Carpena et al., ${ }^{28}$ who found no changes regarding the proximate composition of raw pork meat patties after incorporation of Mediterranean berries or avocado by-products.

The monounsaturated FAs (MUFAs) were the most abundant type of FA among all formulations, with an average percentage of $41.10 \%$ of the total FAs analyzed, followed by saturated (SFA) and polyunsaturated FA (PUFA) compounds, with an average percentage of 31.95 and $25.74 \%$, respectively. As expected, the percentage of PUFAs was considerably higher than those found by other authors in previous studies regarding pork meat without added vegetable oils. ${ }^{29}$ This difference in FA profile may be attributed to the replacement of pork fat by linseed oil in the patties as seed oils are well known to possess high amounts of PUFAs. Similar findings were reported by Delgado-Pando et al. ${ }^{30}$ after replacement of pork fat with olive, linseed or fish oils, and also by Rodríguez-Carpena et al. ${ }^{31}$ after replacement of pork fat with sunflower oil.

Oleic acid (C18:1n-9c), the most abundant MUFA and one of the main FAs determined after all treatments, was found in highest amounts in the CO patties. All patties contained substantial amounts of palmitic (C16:0) and stearic (C18:0) acids as the most abundant SFAs, at an average of 19.64 and $10.93 \%$, respectively. Similar results were obtained in studies on porcine meat. According to Pateiro et al. ${ }^{29}$ who investigated fat oxidation in enriched pâtés, percentages of ca $20-22 \%$ and $10-12 \%$ for palmitic and stearic acids respectively, were observed. On the other hand, linoleic (C16:2n-6) and linolenic (C18:3n-3) acids, the most abundant PUFAs, were also present at a high percentage, with average values of $13.16 \%$ and $11.79 \%$ respectively. These results were predictable, taking into account that linseed oil is very rich in linoleic (15-18\%) and linolenic (50-55\%) acids. Concerning a low-fat pork liver pâté, Delgado-Pando et al. ${ }^{30}$ reported a significant $(P<0.05)$ increase in linoleic and linolenic acids when the pork fat was totally or partially replaced by a mixture of olive, linseed or fish oils.

Omega- 6 and omega-3 FAs are essential fatty acids for humans because of the inability of the human body to synthesize them. Therefore, these FAs must be ingested via the intake of foods or supplements. Nevertheless, the consumption of diets with high amounts of omega- 6 PUFAs and very high $n-6 / n-3$ ratios promotes several diseases, including cardiovascular diseases and certain types of cancer. ${ }^{32}$ On the other hand, high PUFA levels 
Table 2. Effect of addition of Fucus vesiculosus extract and BHT on proximate composition and fatty acid (FA) profile (\% of total FAs) of pork patties on one given day [mean \pm standard error $(n=4)$ ]

Treatment

\begin{tabular}{|c|c|c|c|c|c|c|c|}
\hline & $\mathrm{CO}$ & $\mathrm{BHT}$ & FVE-250 & FVE-500 & FVE-1000 & SEM & Sig. \\
\hline Moisture (\%) & $64.55 \pm 0.90$ & $64.92 \pm 0.47$ & $65.17 \pm 0.98$ & $65.24 \pm 0.20$ & $64.63 \pm 1.42$ & 0.19 & ns \\
\hline Fat (\%) & $13.98 \pm 1.23$ & $13.34 \pm 0.69$ & $13.52 \pm 1.05$ & $13.75 \pm 0.46$ & $13.51 \pm 0.66$ & 0.18 & ns \\
\hline Protein (\%) & $17.22 \pm 1.13$ & $16.81 \pm 0.44$ & $16.70 \pm 0.27$ & $16.54 \pm 0.28$ & $16.60 \pm 0.14$ & 0.13 & ns \\
\hline Ash (\%) & $2.05 \pm 0.04$ & $2.10 \pm 0.03$ & $\begin{array}{l}2.03 \pm 0.04 \\
\text { FA profile }\end{array}$ & $2.04 \pm 0.04$ & $2.09 \pm 0.05$ & 0.01 & ns \\
\hline $\mathrm{C} 14: 0$ & $1.03 \pm 0.01^{b}$ & $0.98 \pm 0.02^{a-c}$ & $1.00 \pm 0.02^{\mathrm{a}}$ & $1.01 \pm 0.01^{a-c}$ & $1.00 \pm 0.02^{a-c}$ & 0.01 & * \\
\hline C16:0 & $19.99 \pm 0.24^{b}$ & $19.24 \pm 0.14^{a-c}$ & $19.65 \pm 0.27^{b}$ & $19.70 \pm 0.11^{b}$ & $19.64 \pm 0.33^{b}$ & 0.07 & ** \\
\hline $\mathrm{C} 16: 1 n-7$ & $1.86 \pm 0.01^{\mathrm{b}}$ & $1.79 \pm 0.02^{a-c}$ & $1.79 \pm 0.03^{a-c}$ & $1.85 \pm 0.03^{b}$ & $1.82 \pm 0.03^{a, b}$ & 0.01 & ** \\
\hline $\mathrm{C} 17: 0$ & $0.18 \pm 0.00$ & $0.18 \pm 0.01$ & $0.18 \pm 0.01$ & $0.18 \pm 0.00$ & $0.18 \pm 0.01$ & 0.00 & ns \\
\hline$C 17: 1 n-7$ & $0.15 \pm 0.00$ & $0.15 \pm 0.00$ & $0.15 \pm 0.01$ & $0.15 \pm 0.00$ & $0.15 \pm 0.01$ & 0.00 & ns \\
\hline C18:0 & $11.05 \pm 0.19$ & $10.79 \pm 0.18$ & $10.97 \pm 0.18$ & $10.93 \pm 0.12$ & $10.93 \pm 0.20$ & 0.04 & ns \\
\hline C18:1n-9t & $0.18 \pm 0.01$ & $0.17 \pm 0.00$ & $0.18 \pm 0.01$ & $0.18 \pm 0.00$ & $0.18 \pm 0.01$ & 0.00 & ns \\
\hline C18:1n-9c & $36.18 \pm 0.08^{c}$ & $35.38 \pm 0.26^{\mathrm{a}-\mathrm{c}}$ & $35.76 \pm 0.38^{\mathrm{a}, \mathrm{b}}$ & $36.06 \pm 0.18^{b, c}$ & $35.68 \pm 0.31^{a, b}$ & 0.08 & $* *$ \\
\hline C18:1n-7c & $2.45 \pm 0.07$ & $2.46 \pm 0.02$ & $2.46 \pm 0.13$ & $2.47 \pm 0.15$ & $2.45 \pm 0.14$ & 0.02 & ns \\
\hline C18:2n-6 & $12.92 \pm 0.06$ & $13.25 \pm 0.21$ & $13.08 \pm 0.23$ & $13.18 \pm 0.48$ & $13.38 \pm 0.16$ & 0.06 & ns \\
\hline C20:0 & $0.20 \pm 0.00$ & $0.19 \pm 0.00$ & $0.20 \pm 0.00$ & $0.19 \pm 0.01$ & $0.20 \pm 0.00$ & 0.00 & ns \\
\hline$C 20: 1 n-9$ & $0.69 \pm 0.03$ & $0.70 \pm 0.02$ & $0.67 \pm 0.02$ & $0.67 \pm 0.02$ & $0.69 \pm 0.03$ & 0.01 & ns \\
\hline C18:3n-3 & $11.28 \pm 0.46$ & $12.68 \pm 0.63$ & $11.94 \pm 1.01$ & $11.40 \pm 0.31$ & $11.63 \pm 1.00$ & 0.19 & ns \\
\hline$C 20: 2 n-6$ & $0.39 \pm 0.00$ & $0.39 \pm 0.01$ & $0.40 \pm 0.02$ & $0.40 \pm 0.01$ & $0.40 \pm 0.02$ & 0.00 & ns \\
\hline$C 20: 4 n-6$ & $0.36 \pm 0.03^{a-c}$ & $0.41 \pm 0.01^{\mathrm{b}}$ & $0.39 \pm 0.01^{\mathrm{a}, \mathrm{b}}$ & $0.40 \pm 0.03^{b}$ & $0.40 \pm 0.01^{\mathrm{b}}$ & 0.01 & * \\
\hline SFA & $32.44 \pm 0.44^{b}$ & $31.38 \pm 0.27^{a-c}$ & $31.99 \pm 0.46^{\mathrm{a}, \mathrm{b}}$ & $32.01 \pm 0.21^{a, b}$ & $31.95 \pm 0.55^{a, b}$ & 0.11 & * \\
\hline MUFA & $41.50 \pm 0.14^{c}$ & $40.65 \pm 0.28^{a-c}$ & $41.01 \pm 0.36^{\mathrm{a}, \mathrm{b}}$ & $41.38 \pm 0.27^{b, c}$ & $40.96 \pm 0.35^{a, b}$ & 0.09 & ** \\
\hline PUFA & $24.96 \pm 0.39^{\mathrm{a}}$ & $26.73 \pm 0.51^{b}$ & $25.81 \pm 0.77^{\mathrm{a}, \mathrm{b}}$ & $25.38 \pm 0.39^{a-c}$ & $25.81 \pm 0.84^{a, b}$ & 0.18 & * \\
\hline$\sum n-3$ & $11.28 \pm 0.46$ & $12.68 \pm 0.63$ & $11.94 \pm 1.01$ & $11.40 \pm 0.31$ & $11.63 \pm 1.00$ & 0.19 & ns \\
\hline$\sum n-6$ & $13.68 \pm 0.07$ & $14.05 \pm 0.22$ & $13.87 \pm 0.26$ & $13.98 \pm 0.51$ & $14.17 \pm 0.17$ & 0.07 & ns \\
\hline$n-6 / n-3$ & $1.21 \pm 0.06$ & $1.11 \pm 0.07$ & $1.17 \pm 0.11$ & $1.23 \pm 0.07$ & $1.23 \pm 0.12$ & 0.02 & ns \\
\hline \multicolumn{8}{|c|}{ 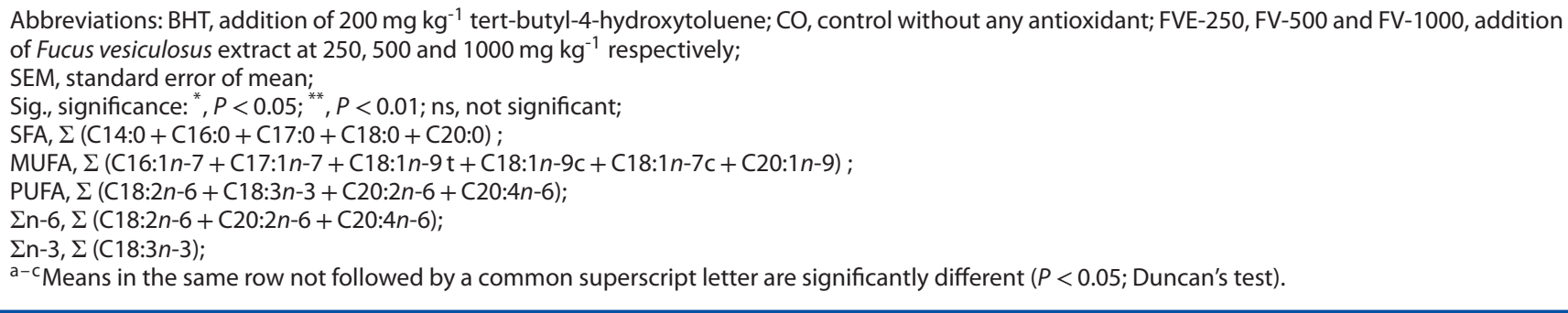 } \\
\hline
\end{tabular}

and low $n-6 / n-3$ ratios induce suppressive effects. ${ }^{32}$ Pork patties in the present study showed $n 6 / n-3$ ratios between 1 and 2 for all treatments, without significant differences $(P>0.05)$. These results are in agreement with the recommendation given by Simopoulos ${ }^{32}$ that the target $n-6 / n-3$ ratio in a healthy diet should be balanced between 1:1 and 2:1.

\section{Effect of FVE on physical properties of pork patties during storage}

The results of the evaluation of $\mathrm{pH}$ and color parameters in pork patties during refrigerated storage are shown in Table 3. The different patty formulations led to significant $\mathrm{pH}$ differences between values at Day $0(P<0.001)$ and Day $18(P<0.01)$. In this regard, Lorenzo et al. ${ }^{3}$ reported higher $\mathrm{pH}$ values during storage of pork patties manufactured with chestnut and seaweed extracts as compared to patties manufactured with tea and grape seed extracts. On the other hand, in the current study, refrigerated storage modified the $\mathrm{pH}$ values of patties in all formulations, with the exception of the FVE-500 treatment. The $\mathrm{pH}$ values were significantly different in the CO- and BHT- $(P<0.01)$ treated patties, and in the FVE-250- $(P<0.05)$ and FVE-1000- $(P<0.001)$ treated patties. A marked decrease was observed at day 11, with the exception of the BHT treatment, after which the $\mathrm{pH}$ increased sharply until Day 15. Following FVE-250 treatment, however, the $\mathrm{pH}$ began to increase at Day 15. Similar results were observed in pork patties with added natural extracts during refrigerated storage. ${ }^{3}$

Different formulations of patties, as well as storage time, also affected the color parameters $L^{*}, a^{*}$ and $b^{*}$. However, the lightness $\left(L^{*}\right)$ did not seem to follow any specific trend over storage time, despite a significant $(P<0.05)$ change after the BHT, FVE-250 and FVE-1000 treatments. The $L^{*}$ values were not affected by different formulations, as previously reported by Lorenzo et al. ${ }^{3}$ Regarding redness $\left(a^{*}\right)$, a progressive loss of red surface color of the patties was noted over storage. Similar trends were observed in other investigations with meats from different species. ${ }^{7}$ The reduction of redness on the patty surface during storage confirmed the appearance of a phenomenon of fading as this process is marked mainly by the loss of $a^{*}$ values, ${ }^{3}$ which is attributed to the metmyoglobin 


\begin{tabular}{|c|c|c|c|c|c|c|c|}
\hline \multirow[b]{2}{*}{ Day } & \multicolumn{5}{|c|}{ Treatment } & \multirow[b]{2}{*}{ SEM } & \multirow[b]{2}{*}{ Sig. } \\
\hline & $\mathrm{CO}$ & BHT & FVE-250 & FVE-500 & FVE-1000 & & \\
\hline 0 & $5.65 \pm 0.02^{a, 1}$ & $5.68 \pm 0.02^{a, b, 1}$ & $5.70 \pm 0.02^{b, 1,2}$ & $5.71 \pm 0.02^{1-3}$ & $5.75 \pm 0.02^{c, 2}$ & 0.01 & $* * *$ \\
\hline 7 & $5.73 \pm 0.04^{2,3}$ & $5.66 \pm 0.10^{1}$ & $5.74 \pm 0.05^{2}$ & $5.75 \pm 0.08$ & $5.74 \pm 0.04^{2}$ & 0.02 & ns \\
\hline 11 & $5.68 \pm 0.03^{1,2}$ & $5.66 \pm 0.01^{1}$ & $5.67 \pm 0.04^{1}$ & $5.65 \pm 0.01$ & $5.65 \pm 0.02^{1}$ & 0.01 & ns \\
\hline 15 & $5.74 \pm 0.02^{3}$ & $5.77 \pm 0.05^{2}$ & $5.66 \pm 0.06^{1}$ & $5.76 \pm 0.09$ & $5.72 \pm 0.03^{2}$ & 0.01 & ns \\
\hline 18 & $5.74 \pm 0.04^{a, b, 3}$ & $5.78 \pm 0.02^{c, 2}$ & $5.76 \pm 0.04^{b, c, 2}$ & $5.71 \pm 0.01^{a-c}$ & $5.72 \pm 0.01^{a, 2}$ & 0.01 & ${ }^{* *}$ \\
\hline SEM & 0.01 & 0.02 & 0.01 & 0.01 & 0.01 & & \\
\hline Sig. & $* *$ & ${ }^{* *}$ & * & ns & $* * *$ & & \\
\hline 0 & $62.09 \pm 1.28$ & $63.11 \pm 1.84^{1,2}$ & $62.01 \pm 0.19^{1}$ & $61.15 \pm 0.51$ & $60.06 \pm 3.02^{1}$ & 0.41 & ns \\
\hline 7 & $61.61 \pm 1.99$ & $65.54 \pm 0.20^{2}$ & $62.31 \pm 2.32^{1}$ & $63.48 \pm 3.81$ & $61.51 \pm 1.39^{1,2}$ & 0.57 & ns \\
\hline 11 & $59.80 \pm 2.47$ & $63.84 \pm 3.43^{1,2}$ & $63.51 \pm 1.53^{1,2}$ & $62.47 \pm 1.72$ & $64.94 \pm 1.76^{2}$ & 0.61 & ns \\
\hline 15 & $64.02 \pm 1.53$ & $61.37 \pm 1.58^{1}$ & $65.72 \pm 2.27^{2}$ & $62.02 \pm 2.35$ & $63.43 \pm 2.20^{1,2}$ & 0.53 & ns \\
\hline 18 & $61.52 \pm 1.78$ & $60.09 \pm 3.16^{1}$ & $61.59 \pm 1.29^{1}$ & $62.79 \pm 2.41$ & $61.99 \pm 1.92^{1,2}$ & 0.48 & ns \\
\hline SEM & 0.48 & 0.64 & 0.48 & 0.51 & 0.57 & & \\
\hline Sig. & $\mathrm{ns}$ & $*$ & $*$ & ns & $*$ & & \\
\hline 0 & $12.03 \pm 0.41 \mathrm{~b}, 3$ & $11.10 \pm 0.96^{a, b, 3}$ & $9.88 \pm 0.64^{a, 3}$ & $10.25 \pm 0.77^{a, 4}$ & $10.33 \pm 1.36^{a, 4}$ & 0.25 & * \\
\hline 7 & $9.35 \pm 1.40^{2}$ & $8.91 \pm 0.62^{2}$ & $9.17 \pm 2.27^{2,3}$ & $8.35 \pm 1.53^{3}$ & $8.70 \pm 1.07^{3}$ & 0.31 & ns \\
\hline 11 & $8.86 \pm 1.40^{2}$ & $8.19 \pm 0.65^{1,2}$ & $7.88 \pm 0.68^{2}$ & $8.08 \pm 0.79^{2,3}$ & $7.18 \pm 0.95^{2}$ & 0.22 & ns \\
\hline 15 & $6.07 \pm 0.87^{1}$ & $7.19 \pm 0.29^{1}$ & $5.62 \pm 0.86^{1}$ & $6.63 \pm 1.05^{2}$ & $7.02 \pm 0.59^{2}$ & 0.21 & ns \\
\hline 18 & $4.72 \pm 0.58^{a, 1}$ & $7.36 \pm 1.30^{b, 1}$ & $4.94 \pm 0.52^{a, 1}$ & $5.07 \pm 0.78^{a, 1}$ & $5.54 \pm 0.65^{a, 1}$ & 0.27 & ** \\
\hline SEM & 0.62 & 0.36 & 0.50 & 0.45 & 0.42 & & \\
\hline Sig. & $* * *$ & $* * *$ & $* * *$ & $* * *$ & $* * *$ & & \\
\hline 0 & $22.51 \pm 0.64^{b, 3}$ & $21.58 \pm 0.51^{a, b, 3}$ & $20.75 \pm 0.77^{a, 2}$ & $20.92 \pm 1.07^{a-c}$ & $21.09 \pm 0.81^{a-c}$ & 0.21 & * \\
\hline 7 & $19.86 \pm 1.07^{2}$ & $19.62 \pm 1.69^{1,2}$ & $20.55 \pm 1.62^{2}$ & $19.81 \pm 2.60$ & $20.85 \pm 1.99$ & 0.39 & ns \\
\hline 11 & $19.36 \pm 0.44^{2}$ & $20.71 \pm 0.64^{2,3}$ & $19.67 \pm 0.70^{1,2}$ & $20.33 \pm 1.12$ & $20.06 \pm 1.30$ & 0.21 & ns \\
\hline 15 & $17.91 \pm 1.65^{\mathrm{a}, 1}$ & $19.10 \pm 0.76^{a, b, 1}$ & $19.18 \pm 1.17^{a, b, 1,2}$ & $19.95 \pm 1.17^{1-3}$ & $20.78 \pm 0.91^{1-3}$ & 0.32 & * \\
\hline 18 & $17.65 \pm 0.30^{1}$ & $18.91 \pm 0.71^{1}$ & $18.04 \pm 1.47^{1}$ & $18.65 \pm 1.06$ & $19.22 \pm 0.71$ & 0.23 & ns \\
\hline SEM & 0.44 & 0.30 & 0.33 & 0.35 & 0.29 & & \\
\hline Sig. & *** & ** & * & ns & ns & & \\
\hline \multicolumn{8}{|c|}{$\begin{array}{l}\text { Abbreviations: BHT, addition of } 200 \mathrm{mg} \mathrm{kg}-1 \text { tert-butyl-4-hydroxytoluene; CO, control without any antioxidant; FVE- } 250, \mathrm{FV}-500 \text { and FV-1000, addition } \\
\text { of Fucus vesiculosus extract at } 250,500 \text { and } 1000 \mathrm{mg} \mathrm{kg}^{-1} \text {, respectively; SEM, standard error of mean; Sig., significance; } \\
{ }^{*}, P<0.05 ;{ }^{* *}, P<0.01 ;{ }^{* * *}, P<0.001 ; \mathrm{ns}, \text { not significant } \\
\text { a-c Means in the same row (different treatments on the same storage day) not followed by a common superscript letter are significantly different } \\
(P<0.05 ; \text { Duncan's test); } \\
1-3 \text { Means in the same column (same treatment in different storage days) not followed by a common superscript number are significantly different } \\
(P<0.05 ; \text { Duncan's test). }\end{array}$} \\
\hline
\end{tabular}

produced through oxidation of myoglobin. From the beginning of storage, patties showed a progressive brownish appearance on the surface until the final storage state. Brown color in pork meat is assigned $\mathrm{a}^{*}$ values ranging between 4.6 and $10.8 .^{33}$

Overall, the addition of antioxidants to pork patties affected redness with progressing time, although differences were only significant at the beginning $(P<0.05)$ and at the end $(P<0.01)$ of the storage period. At Day 0 , patties manufactured with eaweed extract showed lower $a^{*}$ values than CO patties. On the contrary, at Day 18 the result was reversed, i.e. the seaweed antioxidants supported the protection of red color on the patty surface. This stabilizing effect on $a^{*}$ values was also found by other researchers using different natural antioxidants, such as grape seed, $^{3}$ oregano, ${ }^{7,34}$ borage, rosemary ${ }^{34}$ and avocado extracts. ${ }^{28}$ Finally, yellowness $\left(b^{*}\right)$ also decreased over storage time, although less markedly than redness. These results were in good agreement with those obtained by Fernandes et al. ${ }^{7}$ in sheep patties with added BHT and oregano as antioxidants. The different formulations affected the $b^{*}$ values of patties during refrigerated storage.
Greater retention of the color yellow was achieved in treatments with seaweed extract as compared to CO.

Barbut et al. ${ }^{13}$ found that replacement of beef fat with canola oil oleogels made with different amounts of ethylcellulose and sorbitan monostearate induced differences in the lightness and redness of frankfurters. In this context, $L^{*}$ values were increased with fat replacement by oleogel in most of the treatments, although the differences were not significant $(P>0.05)$. Conversely, $a^{*}$ values decreased significantly $(P<0.05)$ in formulations with oleogel. Similar results were obtained for dry fermented sausages with partial pork back-fat replacement by konjac gel. ${ }^{35}$ On the other hand, according to Barbut et al., ${ }^{13}$ the use of canola oil that was not in gel form had a significant $(P<0.05)$ effect on color, in that the $L^{*}$ value increased and the $a^{*}$ value decreased with respect to $C O$. Considering that the addition of a seed (canola) oil generated changes in the surface color of the final patty product, it can be assumed that the addition of linseed oil to our samples induced some modification in the color of patties. This hypothesis is supported by the results reported by Utrilla et al. ${ }^{36}$ who found that higher olive oil 
Table 4. Change of TBARS values during refrigerated storage of pork patties manufactured with different antioxidants $[$ mean $\pm \operatorname{standard~error~}(n=4)]$

\begin{tabular}{|c|c|c|c|c|c|c|c|}
\hline \multirow[b]{2}{*}{ Day } & \multicolumn{5}{|c|}{ Treatment } & \multirow[b]{2}{*}{ SEM } & \multirow[b]{2}{*}{ Sig. } \\
\hline & $\mathrm{CO}$ & BHT & FVE-250 & FVE-500 & FVE-1000 & & \\
\hline & $0.13 \pm 0.00^{e, 1}$ & $0.10 \pm 0.00^{c, 1}$ & $0.09 \pm 0.00^{b, 1}$ & $0.12 \pm 0.00^{d, 1}$ & $0.08 \pm 0.00^{a, 1}$ & 0.00 & $* * *$ \\
\hline 0 & $0.87 \pm 0.17^{2}$ & $0.58 \pm 0.11^{2}$ & $0.74 \pm 0.14^{2}$ & $0.66 \pm 0.13^{1,2}$ & $0.76 \pm 0.15^{2}$ & 0.04 & ns \\
\hline 7 & $1.44 \pm 0.01 \mathrm{~d}, 2$ & $0.78 \pm 0.09^{a, 3}$ & $1.07 \pm 0.01^{b, 2}$ & $1.19 \pm 0.01^{c, 2}$ & $1.09 \pm 0.01^{b, 2}$ & 0.05 & $* * *$ \\
\hline 11 & $3.92 \pm 0.63^{b, 3}$ & $0.96 \pm 0.15^{a, 4}$ & $3.70 \pm 0.59^{b, 3}$ & $3.66 \pm 0.52^{b, 3}$ & $3.54 \pm 0.57^{b, 3}$ & 0.30 & *** \\
\hline 15 & $4.09 \pm 0.66^{b, 3}$ & $1.00 \pm 0.16^{a, 4}$ & $3.87 \pm 0.62^{b, 3}$ & $3.76 \pm 0.75^{b, 3}$ & $3.69 \pm 0.59^{b, 3}$ & 0.31 & $* * *$ \\
\hline 18 & 0.38 & 0.08 & 0.37 & 0.46 & 0.35 & & \\
\hline SEM & $* * *$ & $* * *$ & $* * *$ & $* * *$ & $* * *$ & & \\
\hline Sig. & $0.13 \pm 0.00^{e, 1}$ & $0.10 \pm 0.00^{c, 1}$ & $0.09 \pm 0.00^{b, 1}$ & $0.12 \pm 0.00^{d, 1}$ & $0.08 \pm 0.00^{a, 1}$ & 0.00 & $* * *$ \\
\hline \multicolumn{8}{|c|}{$\begin{array}{l}\text { Abbreviation: } \mathrm{BHT} \text {, addition of } 200 \mathrm{mg} \mathrm{kg}^{-1} \text { tert-butyl-4-hydroxytoluene; } \mathrm{CO}, \text { control without any antioxidant; FVE- } 250, \mathrm{FV}-500 \text { and FV-1000, addition } \\
\text { of Fucus vesiculosus extract at } 250,500 \text { and } 1000 \mathrm{mg} \mathrm{kg}^{-1} \text { respectively; } \\
\text { SEM, standard error of mean; } \\
\text { Sig., significance; }{ }^{* * *}, P<0.001 ; \mathrm{ns} \text {, not significant; } \\
\text { a-e Means in the same row (different treatments on the same storage day) not followed by a common superscript letter are significantly different } \\
(P<0.05 ; \text { Duncan's test); } \\
1-4 \text { Means in the same column (same treatment on different storage days) not followed by a common superscript number are significantly different } \\
(P<0.05 \text {; Duncan's test). }\end{array}$} \\
\hline
\end{tabular}

content in dry-ripened sausages produced higher and lower values of $b^{*}$ and $a^{*}$, respectively, at the beginning of ripening.

\section{Oxidative stability during refrigerated storage of pork patties} Lipid oxidation was quantified in patty samples using the TBARs assay (Table 4). All treatments resulted in a significant $(P<0.001)$ increase in TBARs values during refrigerated storage. According to the results of the present study, patties containing BHT and FVE-1000 had higher oxidative stability than the CO and FVE-250and FVE-500-containing patties (Table 4).

TBARs values increased slightly until day 11, after which an abrupt increase was noted for up to 15 days. Lorenzo et al. ${ }^{3}$ and Sánchez-Escalante et al. ${ }^{34}$ reported similar changes in TBARs values in patties with added natural antioxidants during refrigerated storage. The latter authors found a sharp increase in oxidation from Day 4 (ca $0.8 \mathrm{mg} \mathrm{MDA} \mathrm{kg}^{-1}$ sample) to Day 12 (ca $3.8 \mathrm{MDA}$ $\mathrm{kg}^{-1}$ sample) in the CO. In the present study, oxidation showed a sharp increase with comparable TBARs values $(0.87 \pm 0.17$ and $3.92 \pm 0.63 \mathrm{mg} \mathrm{MDA} \mathrm{kg}^{-1}$ sample respectively). After Day 12, Sánchez-Escalante et al. ${ }^{34}$ observed a stabilization of, and even a slight decrease in, the TBARs values. On the other hand, they noted that these values for some of the patties with added natural antioxidants, such as oregano, rosemary and rosemary with ascorbic acid, remained very stable until Day 16, with values below 1 MDA kg ${ }^{-1}$ sample, and that the values increased sharply until the end of storage, reaching values between 1 and $3 \mathrm{mg} \mathrm{MDA} \mathrm{kg}^{-1}$ sample, lower than those found by us at Day 18 for patties with added seaweed extract.

The evolution of protein oxidation in pork patties during storage is shown in Table 5. A significant $(P<0.01)$ increase in protein oxidation over time was found with all treatments. Similar findings were reported by other authors. ${ }^{7,28}$ Protein oxidation began on Day 7 and increased until the end of storage. The CO patties were the most sensitive to protein oxidation, reaching values of $6.81 \pm 0.61 \mathrm{nmol}$ carbonyl $\mathrm{mg}^{-1}$ protein at Day 18 . The BHT treatment was the most effective, resulting in patties with the lowest carbonyl values. The treatments with FVE reduced the protein oxidation significantly with respect to the $\mathrm{CO}$ without antioxidant at the last day of storage, reaching carbonyl values between 0.77 and $1.15 \mathrm{nmol} \mathrm{mg}^{-1}$ protein. The FVE-1000 treatment also resulted in carbonyl values significantly $(P<0.05)$ lower than those of the $\mathrm{CO}$ at day 15 . This result suggests that addition of FVE decreased the final carbonyl concentrations, especially at $1000 \mathrm{mg}$ extract $\mathrm{kg}^{-1}$ sample. Other natural extracts, such as peel and seed extracts from avocado ${ }^{28}$ and oregano extracts ${ }^{7}$ entailed a delay in carbonyl formation when they were added to pork, beef or sheep meats. Nutritional quality and tenderness are appreciated attributes of meat which are affected by protein oxidation. For this reason its inhibition is important to protect raw meat against these undesirable effects. ${ }^{7}$ The phenolic content found in the FVE probably protected patties against oxidative stress, which delayed the appearance of degradation products.

\section{Effect of FVE on sensory properties of pork patties}

Figures 1 and 2 show the findings of the sensory evaluation of cooked and raw pork patties at Day 0 and at Days 0, 7, 11, 15 and 18 , respectively. Samples cooked at Day 0 did not show any significant differences in odor and taste, independent of treatment. The most significant results can be correlated to the attribute odor, with the highest acceptation received for the FVE-500-treated sample, while no differences in taste preference were found among the CO and the FVE-500- and FVE-1000-treated samples. Bañón et al. ${ }^{37}$ reported similar findings with no appreciable differences in odor and taste preferences at Day 0 in low-sulfite beef patties formulated with green tea and grape seed extracts. Regarding sample preference, no consistent differences were observed among the samples chosen by the panelists as the small differences found in the acceptance test did not seem to influence preference.

Regarding evolution of the sensory properties during refrigerated storage, the surface color and odor attributes of raw samples from all groups studied were given acceptable values until Day 11. From that day on, the acceptability of patties decreased in all treatment groups until it reached the score of 'hardly acceptable' at the end of storage. From Day 11 on, the patties containig BHT received appreciation of color and surface discoloration scores close to acceptability. On the other hand, the FVE-1000 treatment received more favorable color appreciation scores at Day 18 than the rest of 


\begin{tabular}{|c|c|c|c|c|c|c|c|}
\hline \multirow[b]{2}{*}{ Day } & \multicolumn{5}{|c|}{ Treatment } & \multirow[b]{2}{*}{ SEM } & \multirow[b]{2}{*}{ Sig. } \\
\hline & $\mathrm{CO}$ & BHT & FVE-250 & FVE-500 & FVE-1000 & & \\
\hline & $3.57 \pm 0.10^{1}$ & $3.51 \pm 0.19^{1}$ & $3.49 \pm 0.50^{1}$ & $3.53 \pm 0.19^{1}$ & $3.47 \pm 0.14^{1}$ & 0.06 & ns \\
\hline 0 & $3.79 \pm 0.31^{1}$ & $3.52 \pm 0.06^{1}$ & $3.68 \pm 0.05^{1,2}$ & $3.55 \pm 0.10^{1}$ & $3.53 \pm 0.15^{1}$ & 0.04 & ns \\
\hline 7 & $4.58 \pm 0.32^{b, 2}$ & $3.58 \pm 0.04^{a, 1}$ & $4.34 \pm 0.18^{b, 2}$ & $4.51 \pm 0.44^{b, 2}$ & $4.45 \pm 0.51^{b, 2}$ & 0.11 & $* *$ \\
\hline 11 & $5.94 \pm 0.17^{c, 3}$ & $3.79 \pm 0.09^{a, 1,2}$ & $5.40 \pm 0.77^{b, c, 3}$ & $5.31 \pm 0.18^{b, c, 3}$ & $5.14 \pm 0.29^{b, 3}$ & 0.19 & *** \\
\hline 15 & $6.81 \pm 0.61^{c, 4}$ & $4.04 \pm 0.39^{a, 2}$ & $6.04 \pm 0.39^{b, 3}$ & $5.72 \pm 0.27^{b, 3}$ & $5.66 \pm 0.54^{b, 3}$ & 0.23 & $* * *$ \\
\hline 18 & 0.31 & 0.06 & 0.27 & 0.22 & 0.22 & & \\
\hline SEM & $* * *$ & $* *$ & $* * *$ & $* * *$ & $* * *$ & & \\
\hline Sig. & $3.57 \pm 0.10^{1}$ & $3.51 \pm 0.19^{1}$ & $3.49 \pm 0.50^{1}$ & $3.53 \pm 0.19^{1}$ & $3.47 \pm 0.14^{1}$ & 0.06 & ns \\
\hline \multicolumn{8}{|c|}{$\begin{array}{l}\text { BHT, addition of } 200 \mathrm{mg} \mathrm{kg}^{-1} \text { tert-butyl-4-hydroxytoluene; CO, control without any antioxidant; FVE- } 250, \mathrm{FV}-500 \text { and FV- } 1000 \text {, addition of Fucus } \\
\text { vesiculosus extract at } 250,500 \text { and } 1000 \mathrm{mg} \mathrm{kg}^{-1} \text { respectively; } \\
\text { SEM, standard error of mean; } \\
\left.\text { Sig., significance; }{ }^{* * *}, P<0.001\right) \text {; ns, not significant; } \\
\text { a-e Means in the same row (different treatments on the same storage day) not followed by a common superscript letter are significantly different } \\
(P<0.05 ; \text { Duncan's test); } \\
1-4 \text { Means in the same column (same treatment on different storage days) not followed by a common superscript number are significantly different } \\
(P<0.05 \text {; Duncan's test). }\end{array}$} \\
\hline
\end{tabular}

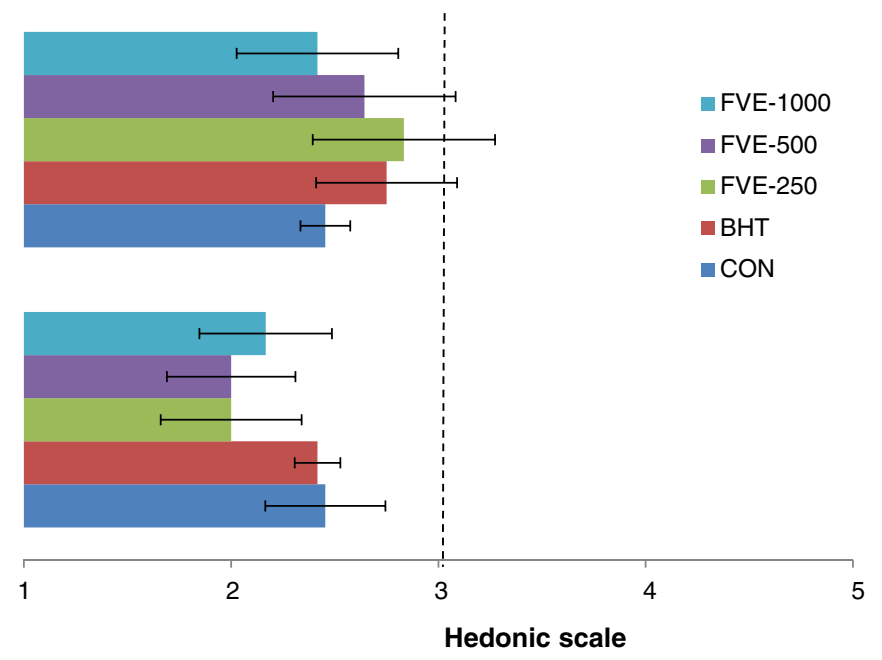

Figure 1. Average sensory scores given to pork patties containing different added extracts.

treatments, but always behind acceptability. Based on the results obtained it may be concluded that FVE, at the concentrations used during the shelf-life of the pork patties, did not improve any of the attributes studied, i.e. color, surface discoloration and odor.

\section{CONCLUSIONS}

In this study, F. vesiculosus extracts were used for the first time as natural preservatives in pork patties. The incorporation of FVE at the concentration of $1000 \mathrm{mg} \mathrm{kg}^{-1}$ into pork patties successfully protected the samples against oxidation, although this treatment was not as effective as the synthetic BHT at the concentration of $200 \mathrm{mg} \mathrm{kg}^{-1}$. One of the key benefits of the preservation technique proposed here, i.e. the use of seaweed extract, was the absence of apparent differences in the sensory attributes of the raw patties studied. Furthermore, the FVE-500 treatment generated the best sensory scores for odor in the cooked product. Despite these results, the limited protection afforded by FVE against oxidation seen under the conditions reported in the present study makes this extract unsuitable for use in meat products. Therefore, increasing the antioxidant power of the extract seems to be the best way to improve fat and protein protection in meat products against oxidation during storage. Further research should explore other potential benefits derived from the incorporation of FVE into meat products, such as nutritional benefits for the consumer.

\section{ACKNOWLEDGEMENTS}

The authors would like to thank Xunta de Galicia (grant number IN607B 2016/28). The authors also thank the Instituto Nacional de Investigaciones Agrarias y Alimentarias, Spain, for granting Ruben Agregán a predoctoral scholarship (CPR2014-0128). Jose M. Lorenzo is a member of the HealthyMeat network, funded by CYTED (ref. 119RT0568). Mohsen Gavahian gratefully acknowledges the support of the Ministry of Economic Affairs, project no. 107-EC-17-A-22-0332, Taiwan (R.O.C). He also would like to declare that his main contribution to this work was related to the extraction and antioxidant studies. Amin Mousavi Khaneghah gratefully 


\section{ODOR}

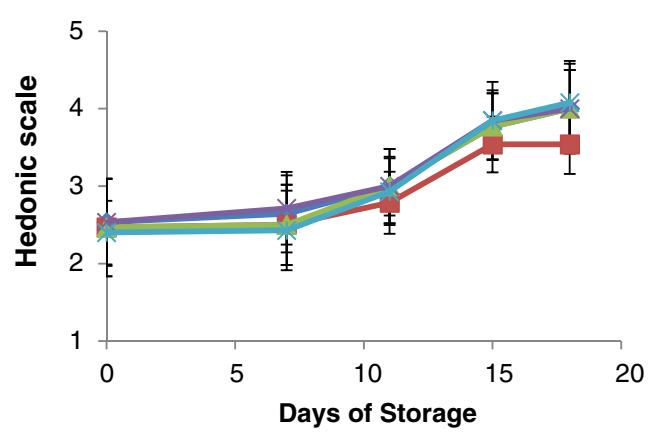

COLOR

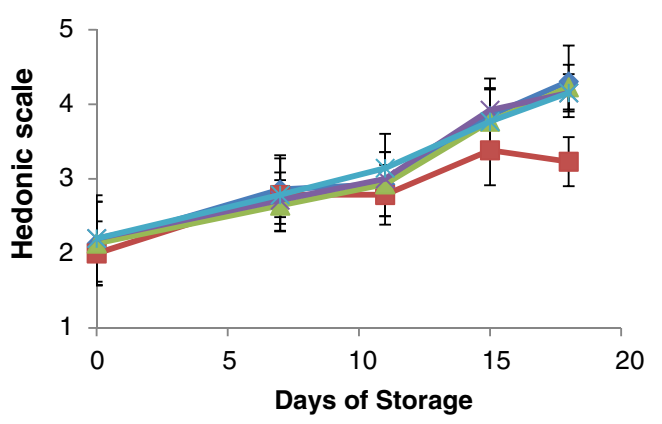

DISCOLORATION AT SURFACE

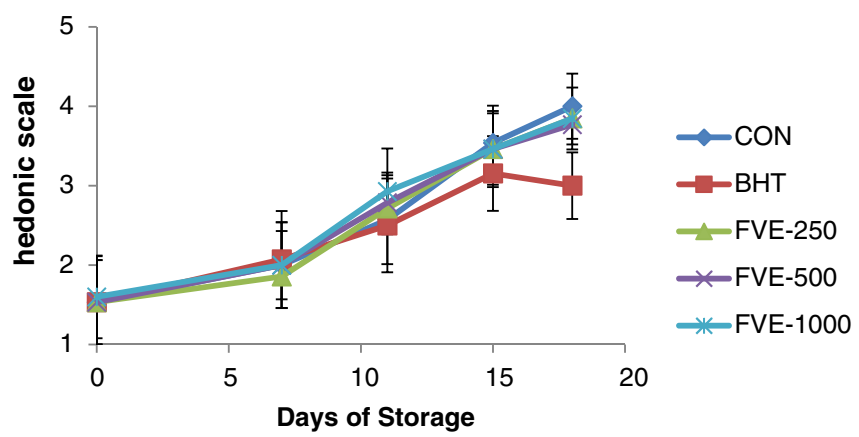

Figure 2. Evolution of color, surface discoloration and odor attributes of raw pork patties with different added extracts during refrigerated storage. Hedonic scale used: 1, excellent; 2 , good; 3 , acceptable; 4, hardly acceptable; 5, not acceptable. Abbreviations: BHT, tert-butyl-4-hydroxytoluene; CO, control; FVE-250, -500 and -1000, Fucus vesiculosus extract at 250, 500 and $1000 \mathrm{mg} \mathrm{kg}^{-1}$, respectively.

acknowledges the support of a CNPq-TWAS Postgraduate Fellowship (Grant \# 3240274290).

Special thanks to Artur J. Martins and Miguel A. Cerqueira for supplying the 'organogels' used in this study.

\section{REFERENCES}

1 Lorenzo JM, Pateiro M, Domínguez R, Barba FJ, Putnik P, Kovačević DB et al., Berries extracts as natural antioxidants in meat products: $A$ review. Food Res Int 106:1095-1104 (2018). https://doi.org/10.1016/ j.foodres.2017.12.005.

2 Carpenter CE, Cornforth DP and Whittier D, Consumer preferences for beef color and packaging did not affect eating satisfaction. Meat Sci 57:359-363 (2001). https://doi.org/10.1016/S0309-1740(00)00 $111-X$.

3 Lorenzo JM, Sineiro J, Amado IR and Franco D, Influence of natural extracts on the shelf life of modified atmosphere-packaged pork patties. Meat Sci 96:526-534 (2014). https://doi.org/10.1016/j .meatsci.2013.08.007.
4 Lund MN, Heinonen M, Baron CP and Estevez M, Protein oxidation in muscle foods: A review. Mol Nutr Food Res 55:83-95 (2011). https:// doi.org/10.1002/mnfr.201000453.

5 Franco D, Rodríguez-Amado I, Agregán R, Munekata PES, Vázquez JA, Barba FJ et al., Optimization of antioxidants extraction from peanut skin to prevent oxidative processes during soybean oil storage. LWT-Food Sci Technol 88:1-8 (2018). https://doi.org/10.1016/j.Iwt .2017.09.027.

6 Granato D, Nunes DS and Barba FJ, An integrated strategy between food chemistry, biology, nutrition, pharmacology, and statistics in the development of functional foods: A proposal. Trends Food Sci Tech 62:13-22 (2017). https://doi.org/10.1016/j.tifs.2016.12.010.

7 Fernandes RPP, Trindade MA, Lorenzo JM, Munekata PES and De Melo MP, Effects of oregano extract on oxidative, microbiological and sensory stability of sheep burgers packed in modified atmosphere. Food Control 63:65-75 (2016). https://doi.org/10.1016/j.foodcont .2015.11.027.

8 Agregán R, Munekata PE, Domínguez R, Carballo J, Franco D and Lorenzo JM, Proximate composition, phenolic content and in vitro antioxidant activity of aqueous extracts of the seaweed Ascophyllum nodosum, Bifurcaria bifurcata and Fucus vesiculosus. Effect of addition of the extracts on the oxidative stability of canola oil under accelerated storage conditions. Food Res Int 99:986-994 (2017). https://doi.org/10.1016/j.foodres.2016.11.009.

9 Agregán R, Munekata PES, Franco D, Carballo J, Barba FJ and Lorenzo $\mathrm{JM}$, Antioxidant potential of extracts obtained from macro- (Ascophyllum nodosum, Fucus vesiculosus and Bifurcaria bifurcata) and micro-algae (Chlorella vulgaris and Spirulina platensis) assisted by ultrasound. Medicines 5:33 (2018). https://doi.org/10.3390/ medicines5020033.

10 Liu X, Yuan W, Sharma-Shivappa R and van Zanten J, Antioxidant activity of phlorotannins from phlorotannins brown algae. Int J Agr Biol Eng 10:184-191 (2017). https://doi.org/10.25165/j.ijabe.20171006 .2854 .

11 Afshari R, Hosseini H, Khaneghah AM and Khaksar R, Physico-chemical properties of functional low-fat beef burgers: Fatty acid profile modification. LWT-Food Sci Technol 78:325-331 (2017). https://doi .org/10.1016/j.Iwt.2016.12.054.

12 Carter JF. Potential of flaxseed and flaxseed oil in baked goods and other products in human nutrition. Cereal Food World (1993).

13 Barbut S, Wood J and Marangoni A, Potential use of organogels to replace animal fat in comminuted meat products. Meat Sci 122:155-162 (2016). https://doi.org/10.1016/j.meatsci.2016.08.003.

14 Totosaus A, Gonzaléz-Gonzaléz R and Fragoso $M$, Influence of the type of cellulosic derivatives on the texture, and oxidative and thermal stability of soybean oil oleogel. Grasas Aceites 67:e152 (2016). https://doi.org/10.3989/gya.0440161.

15 ISO 937:1978 standard. Determination of Nitrogen Content. International Standards Meat and Meat Products. International Organization for Standardization (ISO), Genéve (1978).

16 ISO 1442:1997 standard. Determination of Moisture Content. International Standards Meat and Meat Products. International Organization for Standardization (ISO), Genéve (1997).

17 ISO 936:1998 Standard. Determination of Ash Content. International Standards Meat and Meat Products. International Organization for Standardization (ISO), Genéve (1998).

18 AOCS Official Procedure Am 5-04. Rapid Determination of Oil/Fat Utilizing High Temperature Solvent Extraction. American Oil Chemists Society, Urbana (2005).

19 Mercier Y, Gatellier P and Renerre M, Lipid and protein oxidation in vitro, and antioxidant potential in meat from Charolais cows finished on pasture or mixed diet. Meat Sci 66:467-473 (2004). https://doi .org/10.1016/S0309-1740(03)00135-9.

20 Vyncke W, Direct determination of the thiobarbituric acid value in trichloracetic acid extracts of fish as a measure of oxidative rancidity. Fett Wiss Technol 72:1084-1087 (1970). https://doi.org/10.1002/lipi .19700721218.

21 Macfie HJ, Bratchell N, Greenhoff K and Vallis LV, Designs to balance the effect of order to of presentation and 1st-order carry-over effects in hall test. J Sens Stud 4:129-148 (1989).

22 Wang $T$, Jónsdóttir R and Ólafsdóttir G, Total phenolic compounds, radical scavenging and metal chelation of extracts from Icelandic seaweeds. Food Chem 116:240-248 (2009). https://doi.org/10.1016/ j.foodchem.2009.02.041.

23 Waterman PG and Mole S eds, Analysis of Phenolic Plant Metabolites. Blackwell Scientific Publications, Oxford (1994). 
24 Jiménez-Escrig A, Gómez-Ordóñez E and Rupérez $P$, Brown and red seaweeds as potential sources of antioxidant nutraceuticals. J Appl Phycol 24:1123-1132 (2012). https://doi.org/10.1007/s10811-0119742-8.

25 Farvin KS and Jacobsen C, Phenolic compounds and antioxidant activities of selected species of seaweeds from Danish coast. Food Chem 138:1670-1681 (2013). https://doi.org/10.1016/j.foodchem .2012.10.078.

26 Rajauria G, Jaiswal AK, Abu-Gannam N and Gupta S, Antimicrobial, antioxidant and free radical-scavenging capacity of brown seaweed Himanthalia elongata from western coast of Ireland. J Food Biochem 37:322-335 (2013). https://doi.org/10.1111/j.1745-4514 .2012.00663.x.

27 Connan S, Goulard F, Stiger V, Deslandes E and Gall EA, Interspecific and temporal variation in phlorotannin levels in an assemblage of brown algae. Bot Mar 47:410-416 (2004). https://doi.org/10.1515/ BOT.2004.057.

28 Rodríguez-Carpena JG, Morcuende D and Estévez M, Avocado by-products as inhibitors of color deterioration and lipid and protein oxidation in raw porcine patties subjected to chilled storage. Meat Sci 89:166-173 (2011). https://doi.org/10.1016/j.meatsci.2011 .04 .013 .

29 Pateiro M, Lorenzo JM, Vázquez JA and Franco D, Oxidation stability of pig liver paté with increasing levels of natural antioxidants (grape and tea). Antioxid 4:102-123 (2015). https://doi.org/10.3390/ antiox4010102.

30 Delgado-Pando G, Cofrades S, Rodríguez-Salas L and Jiménez-Colmenero $\mathrm{F}, \mathrm{A}$ healthier oil combination and konjac gel as functional ingredients in low-fat pork liver pâté. Meat Sci 88:241-248 (2011). https://doi.org/10.1016/j.meatsci.2010.12 .028 .
31 Rodríguez-Carpena JG, Morcuende D and Estévez M, Avocado, sunflower and olive oils as replacers of pork back-fat in burger patties: Effect on lipid composition, oxidative stability and quality traits. Meat Sci 90:106-115 (2012). https://doi.org/10.1016/j.meatsci.2011 .06 .007 .

32 Simopoulos AP, The omega-6/omega-3 fatty acid ratio: Health implications. Ocl-Ol Corps Gras Li 17:267-275 (2010). https://doi.org/10 .1051/ocl.2010.0325.

33 De Santos F, Rojas M, Lockhorn G and Brewer MS, Effect of carbon monoxide in modified atmosphere packaging, storage time and endpoint cooking temperature on the internal color of enhanced pork. Meat Sci 77:520-528 (2007). https://doi.org/10.1016/j.meatsci .2007.04.031.

34 Sánchez-Escalante A, Djenane D, Torrescano G, Beltrán JA and Roncales $\mathrm{P}$, Antioxidant action of borage, rosemary, oregano, and ascorbic acid in beef patties packaged in modified atmosphere. J Food Sci 68:339-344 (2003). https://doi.org/10.1111/j.1365-2621 .2003.tb14162.x.

35 Ruiz-Capillas C, Triki M, Herrero AM, Rodriguez-Salas L and Jiménez-Colmenero $F$, Konjac gel as pork backfat replacer in dry fermented sausages: Processing and quality characteristics. Meat Sci 92:144-150 (2012). https://doi.org/10.1016/j.meatsci.2012 .04 .028 .

36 Utrilla MC, Ruiz AG and Soriano A, Effect of partial replacement of pork meat with an olive oil organogel on the physicochemical and sensory quality of dry-ripened venison sausages. Meat Sci 97:575-582 (2014). https://doi.org/10.1016/j.meatsci.2014.03.001.

37 Bañón S, Díaz P, Rodríguez M, Garrido MD and Price A, Ascorbate, green tea and grape seed extracts increase the shelf life of low sulphite beef patties. Meat Sci 77:626-633 (2007). https://doi.org/10.1016/j .meatsci.2007.05.015. 